\title{
Commentary on cloud modelling and the mass accommodation coefficient of water
}

\author{
A. Laaksonen ${ }^{1}$, T. Vesala ${ }^{2}$, M. Kulmala ${ }^{2}$, P. M. Winkler ${ }^{3}$, and P. E. Wagner ${ }^{3}$ \\ ${ }^{1}$ Department of Applied Physics, University of Kuopio, P.O. Box 1627, FIN-70211 Kuopio, Finland \\ ${ }^{2}$ Department of Physical Sciences, University of Helsinki, P.O. Box 64, FIN-00014 Helsinki, Finland \\ ${ }^{3}$ Institut für Experimentalphysik, Universität Wien, Boltzmanngasse 5, A-1090 Wien, Austria
}

Received: 8 September 2004 - Published in Atmos. Chem. Phys. Discuss.: 5 November 2004

Revised: 6 February 2005 - Accepted: 8 February 2005 - Published: 14 February 2005

\begin{abstract}
The mass accommodation coefficient of water is a quantity for which different experimental techniques have yielded conflicting values in the range 0.04-1. From the viewpoint of cloud modelling, this is an unfortunate situation, since the value of the mass accommodation coefficient affects the model results, e.g. the number concentration of activated cloud droplets. In this commentary we note that in cloud modelling, the primary quantity of interest is the droplet growth rate rather than the mass accommodation coefficient, and that experimental investigations of droplet growth rates provide more direct verification of cloud models than do measurements of the mass accommodation coefficient. Furthermore, we argue that the droplet growth rates calculated in cloud model studies are consistent with experimental results obtained so far only if a mass accommodation coefficient of unity is applied.
\end{abstract}

\section{Introduction}

The mass accommodation coefficient $\alpha$ of water vapor molecules on liquid water has been studied experimentally and theoretically for decades with conflicting results. Recent experiments on droplet growth rates (Winkler et al., 2004) indicate a mass accommodation coefficient of unity or near unity, while results from droplet train flow reactors (Li et al., 2001) have yielded values on the order of 0.1-0.3. Even lower values, on the order of 0.04-0.1, were obtained with a technique measuring droplet evaporation rates in an electrodynamic levitation chamber(Shaw and Lamb, 1999) .

The mass accommodation coefficient is a quantity that affects among other things the results obtained with process models simulating cloud droplet growth. A mass accommodation coefficient below unity slows down droplet growth

Correspondence to: A. Laaksonen

(ari.laaksonen@uku.fi) and causes the maximum supersaturation to increase. It has been shown that relatively large increases in cloud droplet number concentrations can result for small decreases in the value of $\alpha$ (Rudolf et al., 2001; Nenes et al., 2001). The values of mass accommodation coefficient applied in recent cloud model studies are between 0.04-1 (Kreidenweis et al., 2003), which undoubtedly causes differences in the model results. In cloud modelling, the primary quantity of interest is the droplet growth rate rather than the mass accommodation coefficient, and it is obvious that experimental investigations of droplet growth rates provide more direct verification of cloud models than do measurements of the mass accommodation coefficient. It is our purpose to point out that the droplet growth rate calculated in cloud model studies is only consistent with experimental results obtained so far if a mass accommodation coefficient of unity is applied.

\section{Discussion}

The condensation theory used in cloud models is the so called transition regime condensation theory. The mass flux directed away from the droplet can be given in the form (Kulmala et al., 1993a,b)

$$
I=\frac{-4 \pi a\left(S-S_{a}\right)}{\frac{R T_{\infty}\left(1+\left(S+S_{a}\right) p_{v e}\left(T_{\infty}\right) / 2 p\right)}{M_{v} \beta_{M} D p_{v e}\left(T_{\infty}\right)}+\frac{S_{a} L^{2} M_{v}}{R \beta_{T} K T_{\infty}^{2}}},
$$

where $a$ is the droplet radius, $S$ is the gas phase activity at ambient (far from the droplet) temperature $T_{\infty}$ and $S_{a}$ is the activity over the droplet surface, $R$ is the gas constant, $M_{v}$ is the molecular weight of the condensing vapour, $D$ is the binary (between vapour and the inert gas) diffusion coefficient at $T_{\infty}, p_{v e}$ is the saturation vapour pressure of the liquid, $L$ is the latent heat of vaporization and $K$ is the heat conductivity of the vapour-gas mixture at the ambient temperature and $p$ is the ambient total gas pressure. This equation has been

(C) 2005 Author(s). This work is licensed under a Creative Commons License. 
derived subject to several approximations which do not lead to significant inaccuracies (see e.g. Vesala et al., 1997).

$\beta_{M}$ is the transition regime correction for mass transfer which has been considered by several workers; e.g. Fukuta and Walter (1970); Sitarski and Nowakowski (1979); Dahneke (1983); Loyalka (1983). Here, we apply the formula derived by Fuchs and Sutugin (1970)

$\beta_{M}=\frac{1+K n}{1+\left(\frac{4}{3 \alpha_{M}}+0.377\right) K n+\frac{4}{3 \alpha_{M}} K n^{2}}$,

where the Knudsen number $K n$ is the ratio of the mean effective free path of the vapour molecules, calculated from the vapour diffusivity, to the droplet radius. $\alpha_{M}$ is now the mass accommodation coefficient. Correspondingly, $\beta_{T}$ is the transitional correction factor for heat transfer

$\beta_{T}=\frac{1+K n_{T}}{1+\left(\frac{4}{3 \alpha_{T}}+0.377\right) K n_{T}+\frac{4}{3 \alpha_{T}} K n_{T}^{2}}$,

where $\alpha_{T}$ is the thermal accommodation coefficient. The Knudsen number $K n_{T}$ for heat transfer is defined analogously to $K n$ by replacing the mean free path of vapour by a length scale for heat transfer, which is provided by the mean effective free path of the carrier gas molecules calculated from the heat conductivity of the inert gas (Wagner, 1982). Clearly, $\alpha_{M}$ refers to water vapour molecules, while $\alpha_{T}$ refers (mainly) to inert air molecules. Note, that the transition regime corrections used in the present study in conjunction with the proper definitions of the Knudsen numbers (Fuchs and Sutugin, 1970) have been found to provide good approximations for molecular mass ratios ranging from values $\ll 1$ (light vapours) up to values exceeding 10 (Qu and Davis, 2001). Similar expressions must also be applied in multicomponent condensation calculations, see e.g. the treatment of nitric acid condensation during cloud formation by Kulmala et al. (1993b).

In calculations of the condensational growth, the equations for mass and heat fluxes are coupled and knowledge of the droplet temperature is required in order to calculate the mass flux. The above expression for the mass flux takes approximately into account the correct droplet temperature due to the latent heat release and under atmospheric conditions the formula very precisely gives the same results as the full coupled equations used by Winkler et al. (2004) (see also Vesala et al., 1997). Furthermore, Fladerer et al. (2002) have shown that the formula is applicable to all growth regimes and to initial conditions of high supersaturation, for which it was not expected to work properly. In their experiments, the supersaturations reached values as high as $1100 \%$, i.e. over three orders of magnitude higher than at typical cloud conditions. Correspondingly, the experimental droplet growth rates were on the order of $50 \mu \mathrm{m} / \mathrm{s}$, whereas typical cloud drop growth rates are three orders of magnitude slower.

Winkler et al. (2004) carried out experiments on the growth rates of water droplets observing growth kinetics in an expansion cloud chamber system. They studied liquid droplets nucleated on Ag particles and growing due to condensation of supersaturated water vapour using the experimental system presented in detail by Wagner et al. (2003). In the experiments, the supersaturations were on the order of $30-40 \%$, and droplet growth rates on the order of $10 \mu \mathrm{m} / \mathrm{s}$. Vapour supersaturation was achieved by adiabatic expansion in a computer controlled thermostated expansion chamber resulting in well defined uniform thermodynamical conditions in the measuring volume. Growth of droplets was observed using the constant-angle Mie scattering (CAMS) detection method (Wagner, 1985) providing absolute, time-resolved and non-invasive simultaneous determination of droplet diameter and number density. Winkler et al. (2004) compared their results with theoretical calculations employing the transition regime condensation correction by Fuchs and Sutugin (1970) with different values of the mass accommodation coefficient. They found agreement only for mass accommodation coefficients in a certain range around unity.

The droplet train apparatus of Li et al. (2001) is based on a fast-moving monodisperse, spatially collimated train of droplets interacting with the gas-phase species $\left(\mathrm{H}_{2}^{17} \mathrm{O}\right.$ or $\mathrm{D}_{2} \mathrm{O}$ ) in trace quantities. The liquid water itself is in equilibrium with its vapor, and the uptake of the trace isotopic species (which is of course out-of equilibrium) does not significantly perturb the bulk phase or the surface of the liquid. Mass accommodation coefficients are obtained from the determination of uptake (condensation) of gas phase isotope in trace amounts combined with calculations using a theory which describes the transport of vapor molecules from the gas phase to the air-water interface, and transfer of the species across the interface, i.e. a different theory than that used by Winkler et al. (2004), and in the cloud models. Attempts have been made to reconciliate the above results (Morita et al., 2004; Davidovits et al., 2004) but so far without success. Both the growth rate and droplet train experiments are carefully designed, and almost an order of magnitude difference in the mass accommodation coefficient seems quite high.

The lowest experimental values measured for $\alpha$ in recent years, between 0.04-0.1, were obtained by Shaw and Lamb (1999). They measured the evaporation rate of droplets suspended in an electrodynamic levitation system within a controlled environment. They used the homogeneous freezing nucleation rate as a way to measure droplet temperatures. The relation between nucleation rate and temperature was obtained from Pruppacher (1995), who derived values for the freezing nucleation rate at temperatures between 244-229 K by making use of a combination of cirrus cloud and laboratory observations, classical nucleation theory, and an assumption that liquid water exhibits a critical point close to $228 \mathrm{~K}$, causing many of the thermal properties and the freezing nucleation rate to diverge. It should be noted that some of the observations used by Pruppacher (1995) may not be completely reliable, and that the homogeneous nucleation theory 


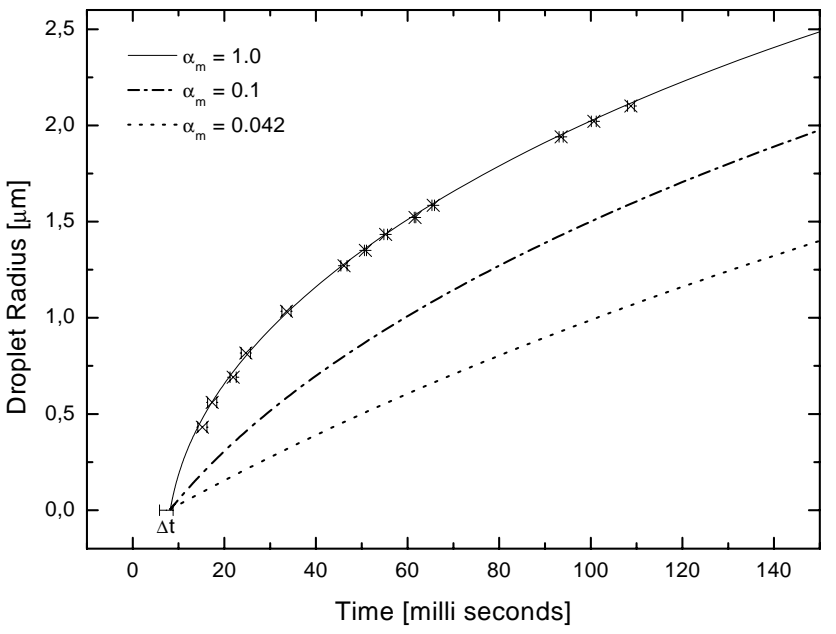

Fig. 1. Experimental results of Winkler et al. (2004) for droplet growth. Theoretical growth curves calculated by means of the transitional drop growth theory (Fuchs and Sutugin, 1970) for mass accommodation coefficients between 0.04 and 1. $\Delta t$ indicates the experimentally determined time interval at the end of expansion, within which the start of droplet growth occurs.

is still a complex, unsolved problem (see e.g. Seinfeld and Pandis, 1998). Furthermore, Huang and Bartell (1995) have shown that it is possible to supercool water clusters down to $200 \mathrm{~K}$ before they freeze (see also Bartell, 1997). Taken together, these facts suggest that the temperature determination of Shaw and Lamb (1999) might be prone to errors.

Figure 1 shows a dataset of droplet growth recorded during the experimental study of Winkler et al. (2004) but not shown in their paper, as well as theoretical growth curves calculated using the transition regime condensation theory, and mass accommodation coefficients ranging from 0.04 to 1. It is clear that only values near unity yield theoretical predictions consistent with the growth rates. Accordingly, the full coupled droplet growth equations accurately predict observations of droplet growth kinetics in an expansion cloud chamber system (Winkler et al., 2004), when the accommodation coefficients $\alpha_{M}$ and $\alpha_{T}$ are set to 1 . Thus the usage of Expressions (1-3) with $\alpha_{M}$ and $\alpha_{T}=1$ is a physically rigorous and consistent approach to estimate the condensational growth. We stress rigor, since many atmospheric scientists are apparently unaware of the recent developments in the condensational growth theories and apply fundamentally incorrect expressions deviating from that given above (see very recent discusssion by Pines et al., 2004 and Vesala et al., 2004). We stress consistency, since the same theory used in the interpretations of the experiments must be fully applied in subsequent atmospheric models. Therefore, as long as the transition regime condensation theory is used in cloud models, the accommodation coefficients should be set to unity. Lower values can lead to too high cloud drop number concentrations, as indicated in Table 1.
Table 1. The effect of accommodation coefficient on cloud drop number concentration (CDNC) calculated using a cloud parcel model (Kulmala et al., 1993b). The aerosol size distribution is lognormal, with a geometric mean deviation of $50 \mathrm{~nm}$, geometric standard deviation of 1.7 , and number concentration of $3000 \mathrm{~cm}^{-3}$. The updraft velocity is $1.0 \mathrm{~m} / \mathrm{s}$ and temperature $273 \mathrm{~K}$.

\begin{tabular}{ll}
\hline$\alpha$ & $\mathrm{CDNC}\left(\mathrm{cm}^{-3}\right)$ \\
\hline 0.04 & 1595 \\
0.1 & 1221 \\
1 & 873 \\
\hline
\end{tabular}

To summarize, comparison with the currently available experimental growth rates indicates that the full coupled FuchsSutugin growth expressions with $\alpha=1$ are in excellent agreement with experiments at saturation ratios between 1.378 (Winkler et al., 2004) and 12 (Fladerer et al., 2002). Furthermore, the simplified equations presented above, suitable for cloud modelling purposes, give very good results at the lower saturation ratio and are in reasonable agreement with the experiments even at $S=12$. Cloud formation occurs at lower saturation ratios than what the currently available growth rate experiments cover; however, there is no fundamental difference in the growth theory which would make high supersaturations and rapid condensation different from low supersaturation and slow condensation. In fact, slow condensation is less prone to errors, since the common assumption of quasistationary growth is less accurate for the case of rapid condensation. Thus, there is very good reason to believe that the transition regime condensation theory with $\alpha=1$ predicts cloud drop growth rates accurately.

\section{Conclusions}

At present, it is not clear whether the real value of $\alpha$ is near 1 or below. If the latter case proves to be correct, this must be associated with a deficiency of the currently used transition regime corrections for droplet growth rates. Whatever the case, the rigorous transition regime growth theory combined with a water vapour thermal and mass accommodation coefficients of unity yields excellent predictions of experimental droplet growth rates. For this reason, the use of mass accommodation coefficient values lower than 1 in cloud models together with the rigorous droplet growth theory is inconsistent and should be avoided.

Acknowledgements. This work was supported by the Academy of Finland (project 201052 and the Center-of-Excellence program) and by the Austrian Science Foundation (FWF, Project No. P16958-N02).

Edited by: G. Feingold 


\section{References}

Bartell, L. S.: On possible interpretations of the anomalous properties of supercooled water, J. Phys. Chem. B, 101, 7573-7583, 1997.

Dahneke, B.: Theory of Dispersed Multiphase Flow, Academic Press, New York, 1983.

Davidovits, P., Worsnop, D. R., Jayne, J. T., Kolb, C. E., Winkler, P., Vrtala, A., Wagner, P. E., Kulmala, M., Lehtinen, K. E. J., Vesala, T., and Mozurkewich, M.: Mass Accommodation coefficient of water vapor on liquid water, Geophys. Res. Lett., 31 (22), L22214, doi:10.1029/2004GL020669, 2004.

Fladerer, A., Kulmala, M., and Strey, R.: Test of the applicability of Kulmala's analytical expression for the mass flux of growing droplets in highly supersaturated systems: growth of homogeneously nucleated water droplets, J. Aerosol. Sci., 33, 391-399, 2002.

Fuchs, N. A. and Sutugin, A. G.: Highly Dispersed Aerosols, Ann Arbor Science Publ., Ann Arbor, Michigan, 1970.

Fukuta, N. and Walter, L. A.: Kinetics of hydrometeor growth from a vapor-spherical model, J. Atmos. Sci., 27, 1160-1172, 1970.

Huang, J. and Bartell, L. S.: Kinetics of homogeneous nucleation in the freezing of large water clusters, J. Phys. Chem., 99, 3924$3931,1995$.

Kreidenweis, S. M., Walcek, C. J., Feingold, G., Gong, W., Jacobson, M. Z., Kim, C.-H., Liu, X., Penner, J. E., Nenes, A., and Seinfeld, J. H.: Modification of aerosol mass and size distribution due to aqueous-phase $\mathrm{SO}_{2}$ oxidation in clouds: Comparison of several models, J. Geophys. Res., 108 (D7), 4213, doi:10.1029/2002JD002697, 2003.

Kulmala, M. and Wagner, P. E.: Mass accommodation and uptake coefficients - a quantitative comparison, J. Aerosol Sci., 32, 833841,2001

Kulmala, M., Vesala, T., and Wagner, P. E.: An analytical expression for the rate of binary condensational particle growth, Proc. R. Soc. Lond. A, 441, 589-605, 1993a.

Kulmala, M., Laaksonen, A., Korhonen, P., Vesala, T., Ahonen, T., and Barrett, J. C.: The effect of atmospheric nitric acid vapor on cloud condensation nucleus activation, J. Geophys. Res., 98 (D12), 22 949-22 958, 1993b.

Li, J. L., Shi, O., Davidovits, P., Worsnop, D. R., Jayne, J. T., and Kolb, C. E.: Mass and Thermal Accommodation Coefficients of $\mathrm{H}_{2} \mathrm{O}(\mathrm{g})$ on Liquid Water as a Function of Temperature, J. Phys. Chem. A, 105, 10627-10634, 2001.

Loyalka, S. K.: Modeling of condensation on aerosols, Prog. Nucl. Energy, 12, 1-8, 1983.
Morita, A., Sugiyama, M., Kameda, H., Koda, S., and Hanson, D. R.: Mass accommodation coefficient of water: molecular dynamics simulation and revised analysis of droplet train/flow reactor experiment, J. Phys. Chem. B, 108, 9111-9120, 2004.

Nenes, A., Ghan, S., Abdul-Razzak, H., Chuang, P. Y., and Seinfeld, J. H.: Kinetic limitations on cloud droplet formation and impact on cloud albedo, Tellus, 53B, 133-149, 2001.

Pines, V., Zlatkowski, M., and Chait, A.: Postnucleation droplet growth in supersaturated gas with arbitrary vapor concentration, J. Chem. Phys., 10 455-10 469, 2004.

Pruppacher, H. R.: A new look at homogeneous ice nucleation in supercooled water drops, J. Atmos. Sci., 52, 1924-1933, 1995.

Rudolf, R., Vrtala, A., Kulmala, M., Vesala, T., Viisanen, Y., and Wagner, P. E.: Experimental study of sticking probabilities for condensation of nitric acid - water vapor mixtures, J. Aerosol Sci., 32, 913-932, 2001.

$\mathrm{Qu}, \mathrm{X}$. and Davis, A. J.: Droplet evaporation and condensation in the near-continuum regime, J. Aerosol Sci., 32, 861-876, 2001.

Seinfeld, J. H. and Pandis, S. N.: Atmospheric Chemistry and Physics, John Wiley and Sons, New York, 1998.

Shaw, R. A. and Lamb, D.: Experimental determination of the thermal accommodation and condensation coefficients of water, J. Chem. Phys., 111, 10659-10 663, 1999.

Sitarski, M. and Nowakowski, B.: Condensation rate of trace vapor on Knudsen aerosols from solution of the Boltzmann equation, J. Colloid Interface Sci., 72, 113-122, 1979.

Vesala, T., Kulmala, M., Rudolf, R., Vrtala, A., and Wagner, P. E.: Models for condensational growth and evaporation of binary aerosol particles, J. Aerosol Sci., 28, 565-598, 1997.

Vesala, T., Kulmala, M., and Wagner, P. E.: Comment on "Postnucleation droplet growth in supersaturated gas with arbitrary vapor concentrations" [J. Chem. Phys., 120, 10 455, 2004], J. Chem. Phys., 121, 8163-8164, 2004.

Wagner, P. E.: Aerosol growth by condensation, in: Aerosol Microphysics II., edited by: Marlow, W. H., Springer-Verlag, Düsseldorf, Germany, 129-178, 1982.

Wagner, P. E.: A constant-angle mie scattering method (cams) for investigation of particle formation processes, J. Colloid Interface Sci., 105, 456-467 1985.

Wagner, P. E., Kaller, D., Vrtala, A., Lauri, A., Kulmala, M., and Laaksonen, A.: Nucleation probability in binary heterogeneous nucleation of water-n-propanol vapor mixtures on insoluble and soluble nanoparticles, Phys. Rev. E, 67, 021605, 1-12, 2003.

Winkler, P. M., Vrtala, A., Wagner, P. E., Kulmala, M., Lehtinen, K. E. J., and Vesala, T.: Mass and thermal accommodation during gas-liquid condensation of water, Phys. Rev. Lett., 93, 075701, $1-4,2004$. 